\title{
Myosin I $\beta$ Is Located at Tip Link Anchors in Vestibular Hair Bundles
}

\author{
Peter S. Steyger, ${ }^{1}$ Peter G. Gillespie, ${ }^{2}$ and Richard A. Baird ${ }^{1}$ \\ ${ }^{1} R$. S. Dow Neurological Sciences Institute, Legacy Good Samaritan Hospital, Portland, Oregon 97209, and ${ }^{2}$ Department \\ of Physiology, Johns Hopkins University, Baltimore, Maryland 21205
}

Recent studies have suggested that myosin I $\beta$ mediates the adaptation of mechanoelectrical transduction in vestibular hair cells. An important prediction of this hypothesis is that myosin I $\beta$ should be found in the side insertional plaque, an osmiophilic hair bundle structure that anchors tip links and is thought to house the adaptation motor. To determine whether myosin I $\beta$ was situated properly to perform adaptation, we used immunofluorescence and immunoelectron microscopy with the monoclonal antibody mT2 to examine the distribution of myosin $\mathrm{I} \beta$ in hair bundles of the bullfrog utricle. Although utricular hair cells differ in their rates and extent of adaptation [Baird RA (1994) Comparative transduction mechanisms of hair cells in the bullfrog utriculus. II. Sensitivity and response dynamics to hair bundle displacement. J Neurophysiol 71:685-705.], myosin I $\beta$ was present in all hair bundles, regardless of adaptation kinetics. Confirming that, nevertheless, it was positioned properly to mediate adaptation, myosin I $\beta$ was found at significantly higher levels in the side insertional plaque. Myosin I $\beta$ was also present at elevated levels at the second tip link anchor of a hair bundle, the tip insertional plaque, found at the tip of a stereocilium. These data support myosin I $\beta$ as the adaptation motor and are consistent with the suggestion that the motor serves to restore tension applied to transduction channels to an optimal level, albeit with different kinetics in different cell types.

Key words: vestibular; hair cell; myosin; adaptation; mechanosensory transduction; stereocilia
Hair cells of the bullfrog's vestibular otolith organs respond to gravity, vibration, and linear acceleration. Saccular hair cells detect with particular sensitivity substrate-borne vibration (Lewis et al., 1982); to ensure optimal sensitivity to their favored stimulus, most cells adapt rapidly to static stimuli (Eatock et al., 1987). By contrast, the utricle responds to both static gravitational and dynamic linear acceleration; accordingly, this organ has several hair cell types, each with a characteristic rate and extent of adaptation (Lewis and Li, 1975; Baird, 1994a,b).

An elastic gating spring controls mechanically sensitive transduction channels of hair cells (Corey and Hudspeth, 1983). The best candidate for this spring is the tip link, an extracellular filament that connects adjacent stereocilia along the axis of sensitivity of a hair cell (Pickles et al., 1984; Furness and Hackney, 1985; Assad et al., 1991). A tip link terminates in osmiophilic structures at the kinociliary side of a stereociliary tip and along the side of the adjacent stereocilium (Furness and Hackney, 1985). The structure at the upper end of the tip link, the side insertional plaque, probably houses the adaptation motor, a forceproducing mechanism hypothesized to encompass a cluster of myosin molecules. In this view, myosin molecules respond to changes in gating spring tension and intracellular $\mathrm{Ca}^{2+}$ by moving the insertional plaque along the stereociliary cytoskeleton, restoring tension to near the original level (Howard and Hudspeth, 1987a,b; Assad and Corey, 1992; Jaramillo and Hudspeth, 1993; Hudspeth and Gillespie, 1994; Gillespie and Corey, 1997).

Although it may operate on different time scales in different

\footnotetext{
Received Feb. 10, 1998; revised April 2, 1998; accepted April 7, 1998.

This work was supported by National Institute on Deafness and Other Communication Disorders Grants DC03028 (P.S.S.), DC02368 (P.G.G.), and DC02040 (R.A.B.) and funds from the Oregon Lions Sight and Hearing Foundation (R.A.B.). P.G.G. is a Pew Scholar in the Biomedical Sciences.

Correspondence should be addressed to Dr. Peter S. Steyger, Oregon Hearing Research Center, Oregon Health Sciences University, 3181 Sam Jackson Park Road, Portland, OR 97201.

Copyright (C) 1998 Society for Neuroscience $\quad 0270-6474 / 98 / 184603-13 \$ 05.00 / 0$
}

hair cell types, adaptation optimizes the tension applied to transduction channels (Howard et al., 1988). For maximal sensitivity to low-frequency stimuli, transduction channels should be poised at the point of maximum slope on the tension-open probability curve, a two- or three-state Boltzmann relation (Corey and Hudspeth, 1983; Hudspeth, 1992). Alternatively, cells responding to high-frequency stimuli should circumvent low-pass membrane filtering by positioning channels where the slope of the curve changes most rapidly (Hudspeth, 1983). Because several piconewtons must be applied through a gating spring before the open probability of a transduction channel reaches either of these positions (Hudspeth, 1992), a mechanism that applies force at rest to gating springs must be a universal feature of sensitive hair cells. Although the adaptation motor applies resting tension and effects adaptation to sustained stimuli, other mechanisms of adaptation also may function simultaneously (Ricci and Fettiplace, 1997).

Thirteen myosin transcripts are expressed in the bullfrog saccule (Solc et al., 1994). Although myosin I $\beta$, VI, and VIIa reside in hair bundles (Gillespie et al., 1993; Hasson et al., 1997), only myosin $\mathrm{I} \beta$ is situated appropriately to mediate adaptation. To test more definitively whether myosin I $\beta$ could be the adaptation motor, we sought to determine whether it was located within or near the side insertional plaque. Because the adaptation motor should be a universal feature in sensitive hair cells, an adaptation motor myosin should be found in all hair cells, regardless of adaptation kinetics. Hair cells of widely ranging adaptation kinetics contained myosin $\mathrm{I} \beta$, and in all cell types this isozyme was associated with tip link anchors, the expected position of the adaptation motor.

\section{MATERIALS AND METHODS}

Materials. Nonimmune antisera, proteolytic enzymes, and reagents used in fixatives and immunochemical buffers were obtained from Sigma (St. Louis, MO), unless otherwise stated. Rhodamine-conjugated phalloidin was purchased from Sigma or Molecular Probes (Eugene, OR). Biotin- 
ylated horse anti-mouse secondary antibodies and rhodamine-conjugated streptavidin were obtained, respectively, from Vector Laboratories (Burlingame, CA) and Amersham (Arlington Heights, IL). Donkey $\gamma$-globulin was purchased from Jackson ImmunoResearch (West Grove, PA), Tween 20 from Bio-Rad (Hercules, CA), Immobilon P from Millipore (Bedford, MA), and sulfosuccinimidyl-3-(4-hydroxyphenyl)propionate (sulfo-SHPP) from Pierce (Rockford, IL). We obtained alkaline phosphatase-coupled goat anti-mouse secondary antibodies from Southern Biotechnology (Birmingham, AL) and 3-(4-methoxyspiro\{1,2dioxetane-3,2'-(5'-chloro)tricyclo[3.3.1.1 ${ }^{3,7}$ ]decan $\}-4$-yl)phenyl phosphate (CSPD) from Tropix (Bedford, MA). Cell-Tak was purchased from Collaborative Biomedical Products, Becton Dickinson (Bedford, MA). Formaldehyde, glycol methacrylate (JB4), Fluoromount, and Aquamount were obtained from Polysciences (Warrington, PA). Electron microscopy supplies, including gold-conjugated antibodies and glutaraldehyde, osmium tetroxide, propylene oxide, Eponate 12, and uranyl acetate, were purchased from Ted Pella (Redding, CA).

Dissection of the utricular macula. Healthy adult bullfrogs (Rana catesbeiana) were anesthetized with $0.2 \% 3$-aminobenzoic acid ethyl ester (MS-222), immersed in crushed ice, and decapitated. The lower jaw was removed, and the utricular maculae were dissected from the membranous labyrinth in chilled, oxygenated HEPES-buffered saline (HBS) containing (in mM): $110 \mathrm{Na}^{+}, 2 \mathrm{~K}^{+}, 4 \mathrm{Ca}^{2+}, 120 \mathrm{Cl}^{-}, 3 \mathrm{D}$-glucose, and 5 HEPES, pH 7.25. Utricular maculae were immersed for 30-45 min in oxygenated HBS containing $50 \mu \mathrm{g} / \mathrm{ml}$ subtilisin Carlsberg (Sigma protease type XXIV) to loosen the otolith membrane; then the digested remains of the otolith membrane were removed with gentle mechanical agitation.

Actin and myosin I $\beta$ labeling. To visualize filamentous actin, we fixed utricular maculae for $2 \mathrm{hr}$ with $4 \%$ formaldehyde in $0.1 \mathrm{M}$ phosphate buffer, $\mathrm{pH} 7.25$, rinsed them in phosphate buffer, and incubated them for 30 min with $0.5 \%$ Triton $\mathrm{X}-100$ and $5 \mu \mathrm{M}$ rhodamine-conjugated phalloidin in PBS $(0.09 \% \mathrm{NaCl}$ in $0.02 \mathrm{M}$ phosphate buffer, $\mathrm{pH} 7.8)$. Phalloidin-labeled maculae were mounted in Fluoromount in depression slides and were observed with fluorescence microscopy.

The visualization of myosin $\mathrm{I} \beta$ required an abbreviated fixation protocol to preserve myosin $\mathrm{I} \beta$ antigenicity. In these experiments the utricular maculae were fixed for $15 \mathrm{~min}$ with $3 \%$ formaldehyde in $0.1 \mathrm{M}$ phosphate buffer, rinsed in PBS, and permeabilized for $10 \mathrm{~min}$ in $0.5 \%$ Triton X-100 in PBS. Nonspecific binding sites were blocked by immersion of the tissue for $30 \mathrm{~min}$ in $5 \%$ normal horse serum and $1 \%$ bovine serum albumin in PBS (PBS $+1 \%$ BSA). Utricular maculae then were incubated for $1 \mathrm{hr}$ in blocking solution containing $10 \mu \mathrm{g} / \mathrm{ml} \mathrm{mT2} \mathrm{(also}$ known as M2; Wagner et al., 1992), a mouse monoclonal antibody raised against bovine adrenal myosin I $\beta$, and were rinsed in PBS $+1 \%$ BSA. For fluorescence microscopy, bound primary antibodies were detected by indirect immunolabeling. Utricular maculae were incubated for $30 \mathrm{~min}$ with biotinylated horse anti-mouse antibodies (1:100 in PBS + 1\% BSA), were washed several times with PBS $+1 \%$ BSA, and were incubated with streptavidin conjugated with Texas Red (1:100 in PBS + 1\% BSA). In some experiments the utricular maculae were embedded in glycol methacrylate (JB4), serially sectioned at $7 \mu \mathrm{m}$; individual cross sections were observed with fluorescence microscopy.

For immunocytochemical controls, primary antibody was replaced with (1) nonimmune mouse serum or (2) primary antibody preadsorbed for 30 min with a synthetic peptide containing the epitope for mT2, located within the tail region of frog myosin I $\beta$ (PVVKYDRKGYKPRRRQLLLT; Metcalf, 1996).

Fluorescence microscopy. Whole-mount maculae and macular cross sections were examined through rhodamine or Texas Red filter sets (Chroma Technology, Brattleboro, VT), using 40× (numerical aperture, 0.9 ) or $63 \times$ (numerical aperture 1.25) oil-immersion Zeiss Plan Apo objectives in a Zeiss Standard 16 microscope (Oberkochen, Germany). Low-power photomicrographs of phalloidin-labeled maculae or myosin $\mathrm{I} \beta$ immunoreactivity were taken with T-Max film (Kodak, Rochester, NY) exposed at 400 or 1600 ASA. For images at higher magnifications, we obtained video images of labeled material via a cooled CCD video camera (model 72, Dage-MTI, Michigan City, IN). Gain and black level controls were set identically for both control and experimental samples. Individual video images were integrated for $50-150 \mathrm{msec}$ to increase sensitivity and averaged 64-128 times with an image acquisition board (Imagraph, Precision Monoscan, Natick, MA) to reduce noise. Resultant video images were corrected with a defocused background image and were adjusted for optimal brightness and contrast.

Hair bundle isolation and immunoblotting. Utricular hair bundle isola- tion used methods similar to those developed for the frog saccule (Gillespie and Hudspeth, 1991). After dissection and adhesion to a Cell-Tak-coated isolation chamber, utricles were incubated for $15 \mathrm{~min}$ with $50 \mu \mathrm{g} / \mathrm{ml}$ subtilisin Carlsberg to assist in otolith membrane removal. To improve recovery of small bundles, we subsequently incubated utricles for $20 \mathrm{~min}$ with $5 \mathrm{~mm}$ sulfo-SHPP, using the conditions described in Gillespie and Hudspeth (1991) for labeling with $N$-hydroxysuccinimide derivatives. If the sulfo-SHPP step was eliminated, bundle recovery was restricted mainly to the large striolar bundles ("striola-rich bundles"). Utricles then were immersed in 3\% molten methoxylated agarose (Sigma type VIIA) at $34^{\circ} \mathrm{C}$ for $3 \mathrm{~min}$ and subsequently were cooled at $4^{\circ} \mathrm{C}$ for 10-15 min. After the agarose formed a firm gel, the maculae were removed mechanically, leaving the hair bundles embedded in agarose. Recoveries of isolated hair bundles were estimated visually (Gillespie and Hudspeth, 1991).

For immunofluorescence the isolated hair bundles, embedded in agarose, were fixed for $15 \mathrm{~min}$ with $1 \%$ formaldehyde in $0.1 \mathrm{M}$ phosphate buffer, permeabilized for $15 \mathrm{~min}$ with $0.5 \%$ Triton-X 100 , and blocked for $30 \mathrm{~min}$ with $4 \mu \mathrm{g} / \mathrm{ml}$ hemoglobin, $250 \mu \mathrm{g} / \mathrm{ml}$ donkey $\gamma$-globulin, and $0.1 \%$ Tween 20 in PBS. Hair bundles were incubated overnight with $20 \mu \mathrm{g} / \mathrm{ml}$ primary antibodies in blocking solution. To demonstrate specificity, we included a $50-100 \mu \mathrm{M}$ concentration of the mT2 epitope peptide in the control samples. After being washed with $0.1 \%$ Tween 20 in PBS, the hair bundles were incubated for $1 \mathrm{hr}$ with $10 \mu \mathrm{g} / \mathrm{ml}$ Cy5-conjugated donkey anti-mouse and $200 \mathrm{nM}$ rhodamine-phalloidin, rinsed in PBS, and mounted with Aquamount. Then the hair bundles were observed with a Zeiss LSM 410 confocal microscope, using $543 \mathrm{~nm}$ and $633 \mathrm{~nm}$ $\mathrm{HeNe}$ lasers and Zeiss C-Apo $40 \times$ (numerical aperture, 1.2) waterimmersion or Zeiss Plan Apo $100 \times$ (numerical aperture, 1.4) oilimmersion objectives.

$S D S-P A G E$ and immunoblotting. Dissected agarose blocks containing hair bundles were heated with SDS-PAGE sample buffer, and samples were separated on $10 \%$ acrylamide, low cross-linker SDS gels (Yamoah and Gillespie, 1996; Hasson et al., 1997). To allow for estimation of recovery, we ran on the same gels samples of recombinant frog myosin I $\beta$, expressed in insect cells, using a baculovirus expression vector (S. Jean and P. Gillespie, unpublished data). Proteins were transferred to Immobilon $\mathrm{P}$ in a solution containing $5 \%$ methanol and $10 \mathrm{~mm}$ 3-(cyclohexylamino)-1-propane sulfonic acid (CAPS), pH 11 (Hasson et al., 1997). Hemoglobin was included in samples and in the gel-incubation solution to facilitate the transfer of small amounts of bundle protein (Gillespie and Gillespie, 1997). Immunoblots were blocked for $2 \mathrm{hr}$ with 5\% Amersham Liquid Block in PBS and then were incubated for an additional $2 \mathrm{hr}$ with $10 \mu \mathrm{g} / \mathrm{ml} \mathrm{mT2}$ in the blocking solution. In early experiments we used biotinylated goat anti-mouse secondary antibodies and streptavidin-alkaline phosphatase, both diluted 1:1000, to detect bound antibody. To avoid the detection of endogenously biotinylated macular proteins, we used alkaline phosphatase-coupled goat anti-mouse secondary antibodies, diluted 1:1000, in later experiments. Chemiluminescence development used CSPD and methods described previously (Gillespie and Hudspeth, 1991). Myosin I $\beta$ was quantified by scanning autoradiograms and comparing the optical density of an unknown with that of purified myosin $\mathrm{I} \beta$ standards.

Transmission electron microscopy. Utricular maculae, fixed with formaldehyde as described above, were permeabilized for $10 \mathrm{~min}$ in $0.1 \%$ Triton X-100 in PBS, blocked for 30 min with 5\% normal horse serum in PBS $+1 \%$ BSA, and were incubated for $1 \mathrm{hr}$ with the primary antibody at $10 \mu \mathrm{g} / \mathrm{ml}$. After being washed, tissue-bound antibodies were localized by incubating maculae for an additional hour with PBS $+1 \%$ BSA containing secondary antibodies conjugated to $3-5 \mathrm{~nm}$ gold particles. Maculae were washed and then post-fixed for $1 \mathrm{hr}$ with $2.5 \%$ glutaraldehyde in PBS and for $1 \mathrm{hr}$ with $1 \%$ osmium tetroxide in PBS. Maculae were dehydrated through an ascending ethanol series and were passaged through 1:1 ethanol/propylene oxide, $100 \%$ propylene oxide, and 1:1 Eponate $12 \mathrm{resin} /$ polypropylene oxide. After maculae were infiltrated with three changes of Eponate 12 resin, resin blocks were polymerized at $60^{\circ} \mathrm{C}$, trimmed, and sectioned with an ultramicrotome (MT2B, DuPont Sorvall, Wilmington, DE). Silver-gold serial sections $(60-70 \mathrm{~nm})$ were collected on colloidin-coated nickel slot grids, counterstained with uranyl acetate, and examined in a Zeiss 10C/A transmission electron microscope at accelerating voltages of 60 or $80 \mathrm{kV}$.

Control organs were treated during the primary antibody incubation step with blocking solution containing (1) no primary antibody, (2) nonimmune mouse serum, or (3) $\mathrm{mT} 2$ preadsorbed with the mT2-epitope 
A

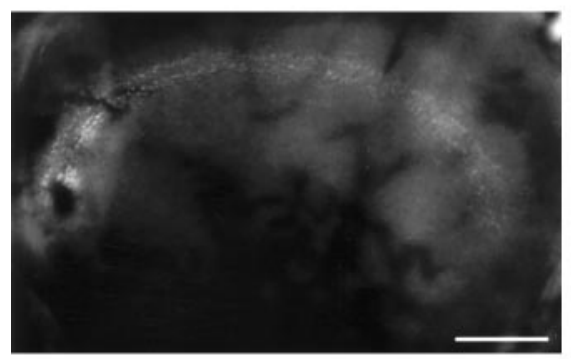

C

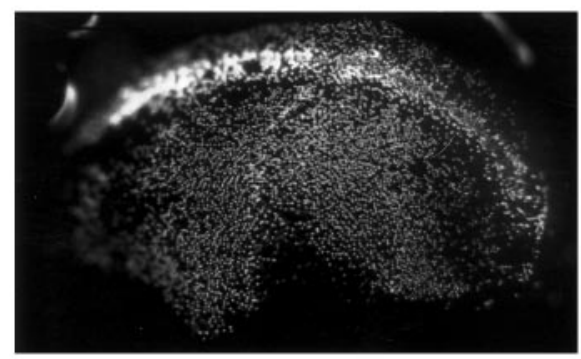

D

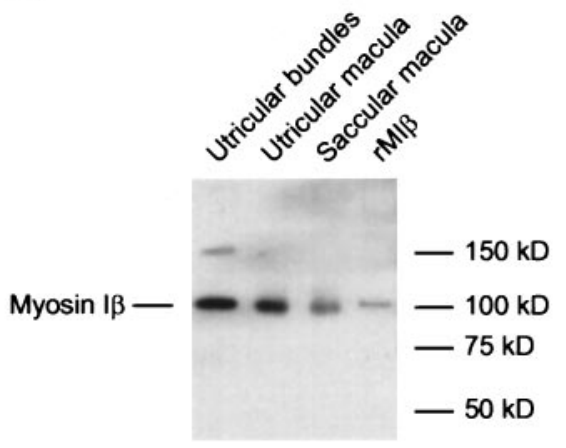

E

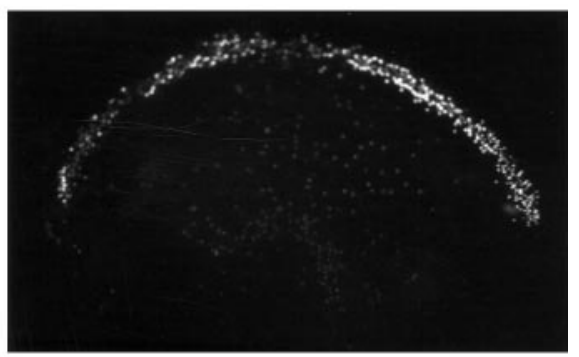

$\mathbf{F}$

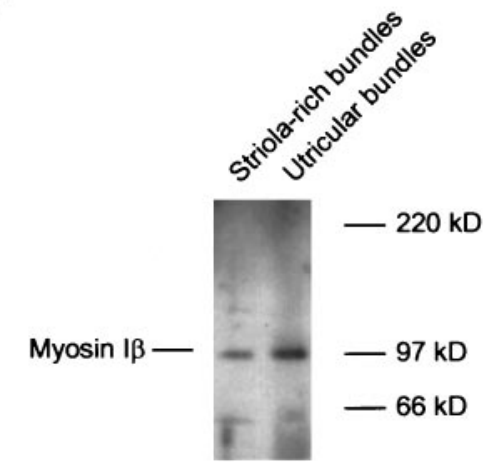

Figure 1. Isolation and protein analysis of utricular hair bundles. $A$, Rhodamine-phalloidin labeling of hair bundles in the whole-mount utricle. $B$, Rhodamine-phalloidin labeling, at higher magnification, of the striola and surrounding medial and lateral extrastriolar regions. The dotted line marks the reversal of hair bundle polarization, dividing the striola into the medial and the lateral zones. MES, Medial extrastriola; $M S$, medial striola; $L S$, lateral striola; $L E S$, lateral extrastriola; $O$, outer striolar rows; $I$, inner striolar rows. $C$, Rhodamine-phalloidin labeling of hair bundles isolated with sulfo-SHPP. $D$, Protein immunoblot labeled with $\mathrm{mT} 2$, a monoclonal antibody against myosin $\mathrm{I} \beta$. mT2 labeled bands at the expected molecular mass of myosin $\mathrm{I} \beta$. Utricular bundles, Hair bundles from $\sim 14$ utricular equivalents; Utricular macula, total protein from one utricular macula; Saccular macula, total protein from one saccular macula; $r M I \beta, 50 \mathrm{pg}$ of recombinant myosin. $E$, Rhodamine-phalloidin labeling of hair bundles isolated without sulfo-SHPP treatment. Note the relative paucity of extrastriolar hair bundles. $F$, Protein immunoblot labeled with mT2 of bundles from striola-rich (without sulfo-SHPP) and whole utricle (with sulfo-SHPP) preparations. Striola-rich bundles, Hair bundles extracted without sulfo-SHPP treatment from $\sim 15$ utricular equivalents; Utricular bundles, hair bundles extracted with sulfo-SHPP treatment from $\sim 7$ utricular equivalents. Scale bars: $150 \mu \mathrm{m}$ in $A, C, E ; 20 \mu \mathrm{m}$ in $B$.

peptide. For preadsorption, $500 \mu \mathrm{M}$ peptide in PBS was mixed for $30 \mathrm{~min}$ with $100 \mu \mathrm{g} / \mathrm{ml} \mathrm{mT2}$; then this solution was diluted 1:10 before use.

Morphometric analyses. Photographic negatives of individual stereocilia containing both tip and side insertional plaques were enlarged to a total magnification of $100,000 \times$. The tip and side plaques were defined, respectively, as the electron-dense regions located at the stereociliary tip and adjacent to a distinct notch in the nonkinociliary side of the stereociliary membrane. Although these structures anchor tip links, because of the harsh conditions required for preembedding immunoelectron microscopy, tip links were observed only rarely. Quantitative analysis of gold particle labeling was performed only on negatives of stereocilia possessing both tip and side plaques. After identifying on a section a stereocilium that contained tip and side plaques, we ensured that this stereocilium was not analyzed on adjacent sections also. Using a $10 \times$ loupe eyepiece, we then verified the shape and diameter of presumptive gold particles on photographic prints and, using transparent overlays, placed a dot over each identified gold particle. Clusters of gold particles were included in our analysis only when individual particles within a cluster could be discerned and counted. For publication, photographic negatives were scanned digitally, and image brightness and contrast were adjusted to optimize the visualization of gold particles and stereociliary structures.

The distribution of gold particles was measured after each stereocilium was divided with spatial bins. To create these bins, we bisected the stereocilium along its longitudinal midline into kinociliary and nonkinociliary halves. Starting at the stereociliary tip, pairs of bins in spatial register, extending $200 \mathrm{~nm}$ along the length of a stereocilium, were placed adjacent to each other across the midline. Gold particles therefore were counted within bins that each encompassed one-half of a stereocilium horizontally and $200 \mathrm{~nm}$ longitudinally.

Our initial analysis suggested that gold particles were located prefer- entially in bins containing the tip or side insertional plaques. To test this hypothesis further, we counted the number of gold particles located within a series of $75 \mathrm{~nm}$ square bins, centered on the side plaque and continuing apically and basally on the nonkinociliary side of the stereociliary shaft. A control analysis was performed on the kinociliary side of the stereociliary shaft, using bins in spatial register with those on the nonkinociliary side. Paired bins extended to a point $\sim 200 \mathrm{~nm}$ below the tip plaque. In addition, to compare the amount of gold immunoreactivity immediately surrounding the tip and side plaques, we counted the number of gold particles located within a $100 \mathrm{~nm}$ diameter arc centered on these structures. We then determined the average gold particle density by dividing the number of gold particles by the area of each arc contained within the stereocilium.

Statistical procedures. Unless otherwise stated, statistical comparisons of morphometric data were based on a one-way ANOVA. Where appropriate, post hoc pairwise multiple comparisons were performed with the Tukey multiple comparison test, adjusting, when necessary, for unequal group sizes.

\section{RESULTS}

\section{Phalloidin labeling of utricular hair bundles}

We examined the distribution of myosin $\mathrm{I} \beta$ in hair bundles of the bullfrog's utricle. To visualize utricular hair bundles, we labeled bullfrog utricles with rhodamine-phalloidin. At low magnification, phalloidin labeling clearly revealed the shape of the sensory epithelium and the presence of the striola, a characteristic curved band of larger hair bundles, near the abneural edge of the macula (Fig. 1A). At higher magnifications (Fig. $1 B$ ) we could visualize 
the shape and size of individual hair bundles and could observe circumferential actin belts, which circumscribe hair cells at the level of the adherens junctions. As previously described (Baird, 1994a,b), cells within the striola generally had larger bundles and were packed less densely than hair cells in the surrounding medial and lateral extrastriolar regions. Within the striola, hair cells abruptly reversed their bundle polarization about a line located near the lateral edge of the striolar region (dashed line, Fig. 1B). Hair cells in the inner striolar rows immediately adjacent to this line were smaller and less densely packed than those in the adjacent outer striolar rows. This pattern of hair bundles coincides with the known distribution of hair cells with differing adaptation kinetics: Type $\mathrm{C}$ and Type $\mathrm{F}$ hair cells in the outer striolar rows adapt rapidly, Type $\mathrm{C}$ and Type $\mathrm{E}$ hair cells in the inner striolar rows adapt more slowly, and Type B hair cells in the medial and lateral extrastriolar regions display little or no adaptation over a time scale of several seconds (Baird, 1992, 1994b).

\section{Hair bundle isolation and myosin I $\beta$ immunoblotting}

To identify and localize myosin $\mathrm{I} \beta$ within utricular hair bundles, we used the monoclonal antibody mT2 (also known as M2; Wagner et al., 1992). The specificity of $\mathrm{mT} 2$ for myosin $\mathrm{I} \beta$ has been confirmed by epitope-mapping studies, which localized highaffinity antibody binding to a 12-amino-acid region with no more than four identical amino acids in any other known myosin I (Metcalf, 1996). In some experiments described below, we used a synthetic peptide containing this region to demonstrate the specificity of mT2 labeling.

To isolate utricular hair bundles and confirm that these bundles contain myosin $\mathrm{I} \beta$, we adapted the "twist-off" isolation used to purify hair bundles from the bullfrog's saccule (Gillespie and Hudspeth, 1991). The undulating shape of the utricle and the large number of small hair bundles introduced challenges that had not been faced with saccular hair bundle isolation. Because utricles did not adhere well to the Cell-Tak-coated experimental chamber, we used an agarose that remained molten at $34^{\circ} \mathrm{C}$ for an extended period of time; this extra time allowed us to reposition utricles that had detached from the bottom of the chamber during agarose irrigation. In addition, to isolate the small extrastriolar hair bundles that constituted the majority of utricular bundles, we found it necessary to modify surface amino groups with the water-soluble $N$-hydroxysuccinimide sulfo-SHPP. We also took advantage of the poor recovery of extrastriolar hair bundles when we were not using sulfo-SHPP to isolate hair bundles preferentially from the striolar region. Although the mechanism of action of sulfo-SHPP modification is unknown, this reagent also enhances the recovery of saccular hair bundles (P. Gillespie, unpublished data). When sulfo-SHPP was used, recoveries of utricular hair bundles ranged from 50 to $100 \%$, comparable to recoveries of saccular hair bundles.

Phalloidin labeling of isolated utricular hair bundles in agarose with (Fig. $1 C$ ) or without (Fig. $1 E$ ) sulfo-SHPP treatment revealed that the distinctive distribution patterns of striolar and extrastriolar hair bundles were retained after isolation and closely corresponded to those seen in intact maculae (Fig. 1A). In particular, the striolar and extrastriolar regions were identified easily, and the smaller, more dispersed hair bundles of the inner striola rows were distinguished readily from the larger hair bundles of the outer striolar rows (Fig. $1 B, C$ ).

Using $\mathrm{mT} 2$, we found that purified utricular hair bundles contained myosin $\mathrm{I} \beta$ in substantial amounts (Fig. $1 D$ ). Hair bundle myosin I $\beta$ comigrated with myosin I $\beta$ from whole saccular macula and from whole utricular macula at $\sim 105 \mathrm{kDa}$, the migration position for myosin $\mathrm{I} \beta$ in low cross-linker polyacrylamide gels (Fig. $1 D$ ). Other bands, seen in addition to the myosin $\mathrm{I} \beta$ monomer, were observed only sporadically. Utricular hair bundle myosin $\mathrm{I} \beta$ migrated slightly faster than recombinant frog myosin $\mathrm{I} \beta$, which was $\sim 3 \mathrm{kDa}$ larger because of its $\mathrm{N}$-terminal fusion partner. By quantitative immunoblotting, we estimated that the hair bundles of one utricle contained $22 \pm 10 \mathrm{pg}$ of myosin I $\beta$. Although this value is considerably larger than that for saccular hair bundles (3 pg; Gillespie et al., 1993), conversion by the relative number of bundles per organ (Baird and Schuff, 1994) and the average number of stereocilia per bundle (Baird, 1994a) indicates that the amount of myosin $\mathrm{I} \beta$ per stereocilium is only approximately fourfold greater in the utricle. There was approximately fourfold more myosin $\mathrm{I} \beta$ per utricular equivalent of bundles in the entire utricle preparation than in the striola-rich preparation (Fig. $1 F$ ) (data not shown). These results demonstrate that $\mathrm{mT} 2$ detects myosin $\mathrm{I} \beta$ in utricular hair bundles.

Confirming that myosin molecules were present in utricular hair bundles, photoaffinity labeling of utricular bundle proteins with $\left[\alpha-{ }^{32}\right.$ P]UTP and vanadate (Gillespie et al., 1993) identified proteins of 105 and $230 \mathrm{kDa}$, probably myosin $\mathrm{I} \beta$ and myosin VIIa (Hasson et al., 1997) (data not shown).

\section{Fluorescence microscopy}

When we used mT2 to label intact utricular maculae, we found that immunofluorescence corresponding to myosin $\mathrm{I} \beta$ was present in utricular hair bundles throughout the striola (Fig. $2 B$ ) and the surrounding medial (Fig. 2A) and lateral (Fig. 2C) extrastriolar regions. Myosin $\mathrm{I} \beta$ was also present in supporting cell apices (data not shown), as previously reported for the saccule (Gillespie et al., 1993). Close examination of whole-mount utricles and resinembedded cross sections (Fig. 2D) indicated that striolar and extrastriolar hair bundles were labeled in their entirety. Hair bundles in the inner striolar rows, primarily belonging to cells with slow adaptation kinetics (Baird, 1992, 1994b), were labeled less intensely than bundles of nonadapting Type B hair cells in extrastriolar regions (Fig. $2 A, C, D$ ) and bundles of rapidly adapting hair cells in outer striolar rows (Fig. $2 B, D$ ). In control experiments in which primary antibodies were omitted (data not shown), replaced with nonimmune mouse serum (Fig. 2E), or preadsorbed with mT2-epitope peptide (Fig. $2 G$ ), no immunoreactivity was visible in utricular hair bundles (compare Fig. 2, $E$ and $F ; G$ and $H$ ). Under each of these control conditions, only weak, nonspecific reactivity was visible within the macula, usually within blood vessels.

We also examined the distribution of myosin $\mathrm{I} \beta$ in hair bundles isolated from the utricular macula. When agarose-embedded utricular hair bundles were double-labeled for filamentous actin (Fig. $3 A$ ) and myosin $\mathrm{I} \beta$ (Fig. 3B), generally similar labeling patterns were observed with the two reagents. One exception, however, was that the inner striolar bundles of slowly adapting hair cells contained less myosin $\mathrm{I} \beta$ than bundles in the outer striolar rows, derived primarily from rapidly adapting hair cells (Fig. 3B). $Z$-series projections taken at different focal planes indicated that myosin $\mathrm{I} \beta$ immunoreactivity was present throughout the length of all hair bundles. Confirming that the antibody recognized myosin $\mathrm{I} \beta$, the synthetic $\mathrm{mT} 2$ peptide reduced nearly completely the mT2 labeling (Fig. 3C,D). When higher magnification pseudo-color images of rhodamine-phalloidin (red) and mT2 (green) labeling were combined digitally, hair bundles with both filamentous actin and myosin I $\beta$ labeling appeared yellow- 

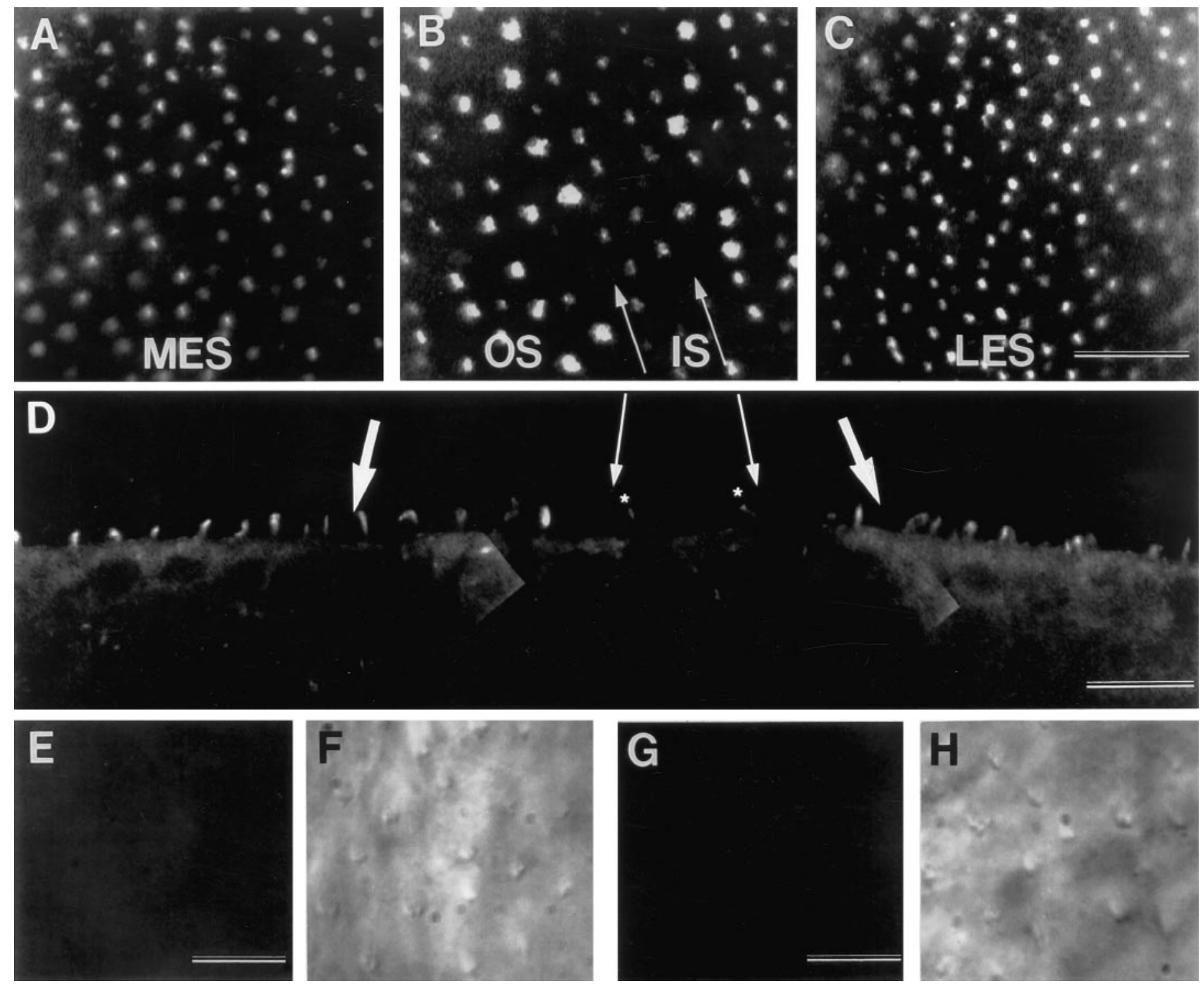

Figure 2. Immunofluorescence localization of myosin I $\beta$ in utricular hair cells. $A-C, \mathrm{mT} 2$ labeling in whole-mount utricles. $A$, Medial extrastriolar region (MES). B, Striola. Arrows mark the borders between the inner striolar (IS) rows and the medial (left) and lateral (right) outer striolar $(O S)$ rows. Note that hair bundles in the inner striolar rows are labeled less intensely than those in the extrastriolar regions and outer striolar rows. $C$, Lateral extrastriolar region (LES). D, mT2 labeling in a cross section of the utricular macula. Large arrows mark the medial (left) and lateral (right) edges of the striola region; small arrows mark the borders between the inner striolar rows and the medial (left) and lateral (right) outer striolar rows. Note that immunoreactivity occurs throughout extrastriolar and outer striolar hair bundles and that inner striolar hair bundles (asterisks) are immunolabeled less intensely than hair bundles in the extrastriolar and outer striolar rows. $E-H$, Control experiments. Fluorescence $(E, G)$ and differential interference contrast (DIC; $F, H)$ images of medial extrastriolar hair bundles were obtained after mT2 was replaced with nonimmune mouse serum $(E, F)$ or preadsorbed with a synthetic peptide derived from the tail region of bullfrog myosin $\mathrm{I} \beta(G, H)$. Note that fluorescence was abolished under both control conditions. Scale bars: $50 \mu \mathrm{m}$ in $A-D ; 25 \mu \mathrm{m}$ in $E-H$.

brown (Fig. 3E). Hair bundles in the inner striola, with strong filamentous actin labeling and little myosin I $\beta$ immunoreactivity, appeared red. Modest amounts of Cy5 fluorescence not associated with hair bundles were also present; this signal ( green in Fig. $3 E$ ) corresponded to $\mathrm{mT} 2$ binding to the agarose gel or structures trapped within it.

\section{Transmission electron microscopy}

To confirm the localization of myosin I $\beta$ obtained from immunofluorescence experiments and to refine its localization by using the higher resolution afforded by immunoelectron microscopy, we used a preembedding procedure, using secondary antibodies conjugated with 3-5 nm gold particles. Control experiments, includ- ing omission of the primary antibody, substitution of the primary antibody with nonimmune mouse serum, or preadsorption of the primary antibody with synthetic myosin peptides, showed that nonspecific immunoreactivity was negligible (Fig. 4).

mT2 gave a robust labeling of utricular cells, particularly hair cells. Gold particles corresponding to myosin I $\beta$ were observed in the microvilli of hair cells and supporting cells (data not shown) and in the cell apices and stereocilia of extrastriolar (arrowheads, Fig. 5) and striolar (arrowheads, Fig. 6) hair cells. In stereocilia, gold particles were located preferentially close to the cell membrane, throughout the length of each stereocilium (Figs. $5 B-D$, $6 B, C)$. Gold particles were observed at the ankle region at the 

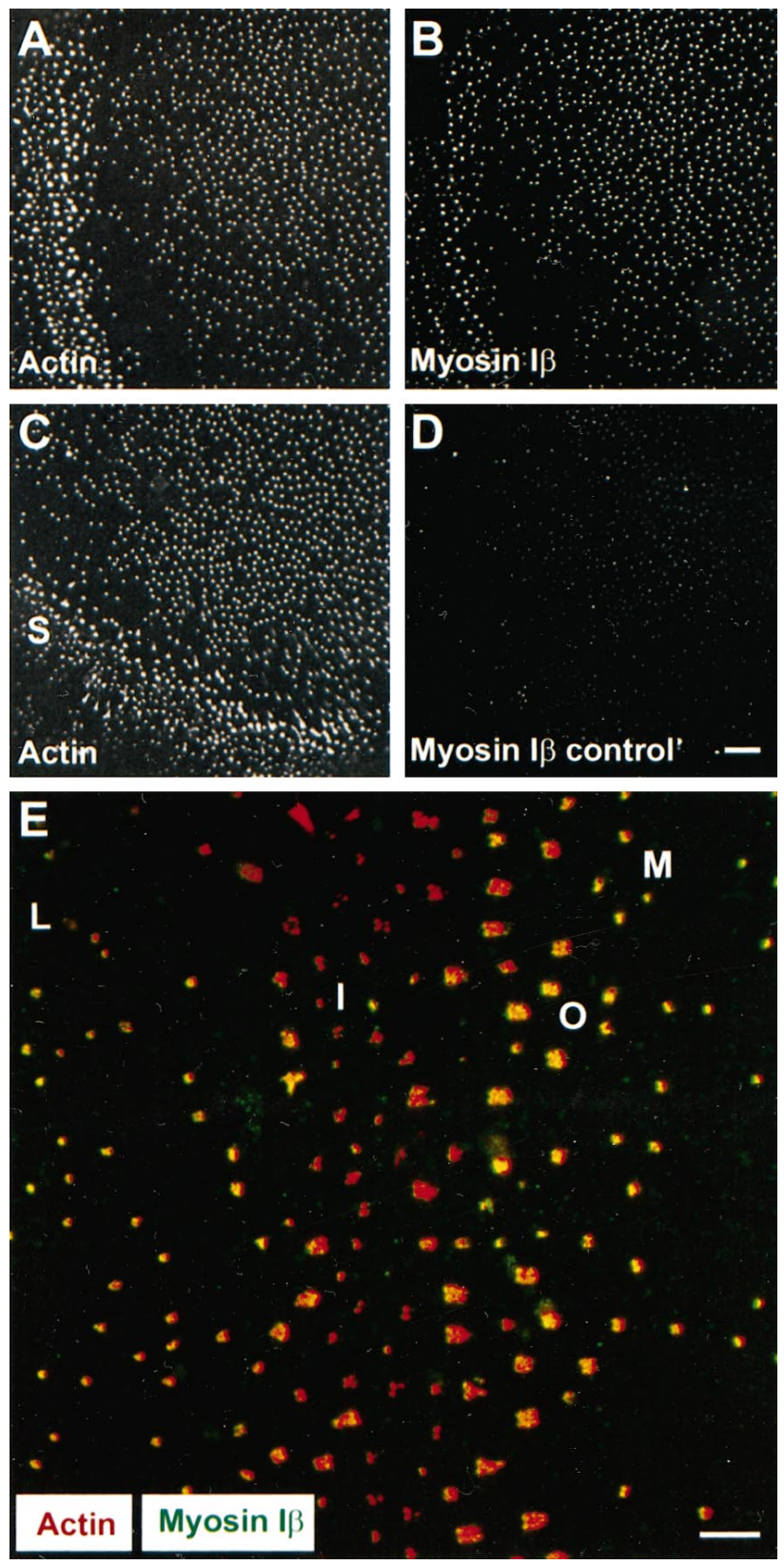

Figure 3. Immunofluorescence localization of myosin I $\beta$ in isolated utricular hair bundles. $A-D$, Isolated agarose-embedded utricular hair bundles were double-labeled with rhodamine-phalloidin $(A, C)$ and $\mathrm{mT} 2$ $(B, D)$. Hair bundles in all regions contain filamentous actin; hair bundles in the inner striolar contain less myosin $\mathrm{I} \beta$ than do bundles in the outer striolar rows and surrounding extrastriolar regions $(B)$. When $\mathrm{mT} 2$ was preadsorbed with a synthetic peptide derived from the tail region of bullfrog myosin $\mathrm{I} \beta$, negligible immunoreactivity was seen in utricular hair bundles. $D, E$, Superimposed high power pseudo-color images of hair bundles labeled with rhodamine-phalloidin (red) and mT2 (green). Hair bundles with both filamentous actin and myosin I $\beta$ labeling appear yellowbrown; hair bundles in the inner striolar rows with strong actin labeling and weak myosin $\mathrm{I} \beta$ labeling appear red; antibody reactivity unassociated with hair bundles appears green. Scale bars: $50 \mu \mathrm{m}$ in $A-D ; 10 \mu \mathrm{m}$ in $E$.

stereociliary base, particularly at the junction where the stereociliary membrane meets with the apical membrane of the hair cell (arrowheads, Fig. 5B). Gold particles also were found along the stereociliary rootlet within the cuticular plate (arrow, Fig. 5B).

If myosin $\mathrm{I} \beta$ is the adaptation motor of the hair cell, then this myosin should be associated with the osmiophilic structure at the upper end of the tip link, the side insertional plaque, which is thought to house the motor molecules. We observed gold particles in and around the side plaques in both extrastriolar (arrowheads, Fig. 5C,D) and striolar (arrowheads, Fig. 6B,C) hair cells. In addition, gold particles frequently were found on the second osmiophilic structure associated with tip links, the tip insertional plaque. This structure is located on the kinociliary side of each stereociliary tip, at the base of a tip link; like the side plaque, the tip plaque may contain structures that are important for transduction and adaptation. Gold particles were observed more frequently around the interior edges of the plaques rather than within them and also frequently were observed immediately above and below the side plaques.

The small gold particles used in this study were difficult to see on negatives of stereociliary sections without further magnification. When higher accelerating voltages were used $(80 \mathrm{kV})$, gold particles were easier to distinguish, but the opacity of the tip and side plaques decreased (Fig. 5D). Larger gold particle sizes did not work with our protocol; this protocol nonetheless was preferred because of the greater ultrastructural preservation as compared with that obtained with protocols that used greater concentrations of or longer exposure to detergent.

\section{Morphometric analysis}

To confirm that myosin $\mathrm{I} \beta$ was located in the side and tip insertional plaques at levels significantly higher than adjacent areas, we sectioned stereocilia parallel to the plane of symmetry of the bundle and counted gold particles along the stereociliary shaft. We only examined sections that contained both a side and a tip plaque. Within the 64 individual stereocilia from 19 hair bundles that met this criterion, we counted the number of gold particles in rectangular bins paired across the midline of each stereocilium (Fig. $7 A$ ). In our initial analysis we used pairs of bins that began at stereociliary tips and continued in $200 \mathrm{~nm}$ increments basally toward the stereociliary rootlet. Each pair of bins included one from the kinociliary side of a stereocilium and one from the nonkinociliary side.

The mean number of gold particles per bin was greatest near the stereociliary tip and decreased significantly in more basal locations (Fig. 7C,E). This trend was most apparent on the kinociliary side of stereocilia, the side at which the tip plaque was always found (Fig. 7B).

On the nonkinociliary side of the stereocilium, the mean number of gold particles was greatest in the second bin from the tip and decreased for successively basal bins (Fig. 7E). The less striking concentration of gold particles in any particular nonkinociliary bin appeared to be attributable to the variable location of the side plaque relative to the tips of the stereocilia. The side plaque was located in the second bin from the tip in only $50 \%$ of stereocilia; the remaining side plaques were located mainly in more basal locations (Fig. 7D). This was particularly true for inner striolar hair bundles, in which $>75 \%$ of stereocilia had side plaques located $400 \mathrm{~nm}$ or more from the stereociliary tip.

For each stereocilium we compared the number of gold particles in bins containing tip plaques, bins containing side plaques, and bins without a plaque (Table 1). The overall gold immunoreactivity in Type $\mathrm{F}$ hair bundles was significantly greater than in other hair bundle types $(p<0.001)$. In addition, the number of gold particles in extrastriolar and outer striolar hair bundles was significantly greater than in inner striolar hair bundles $(p<0.05)$, confirming our immunofluorescence observations. 

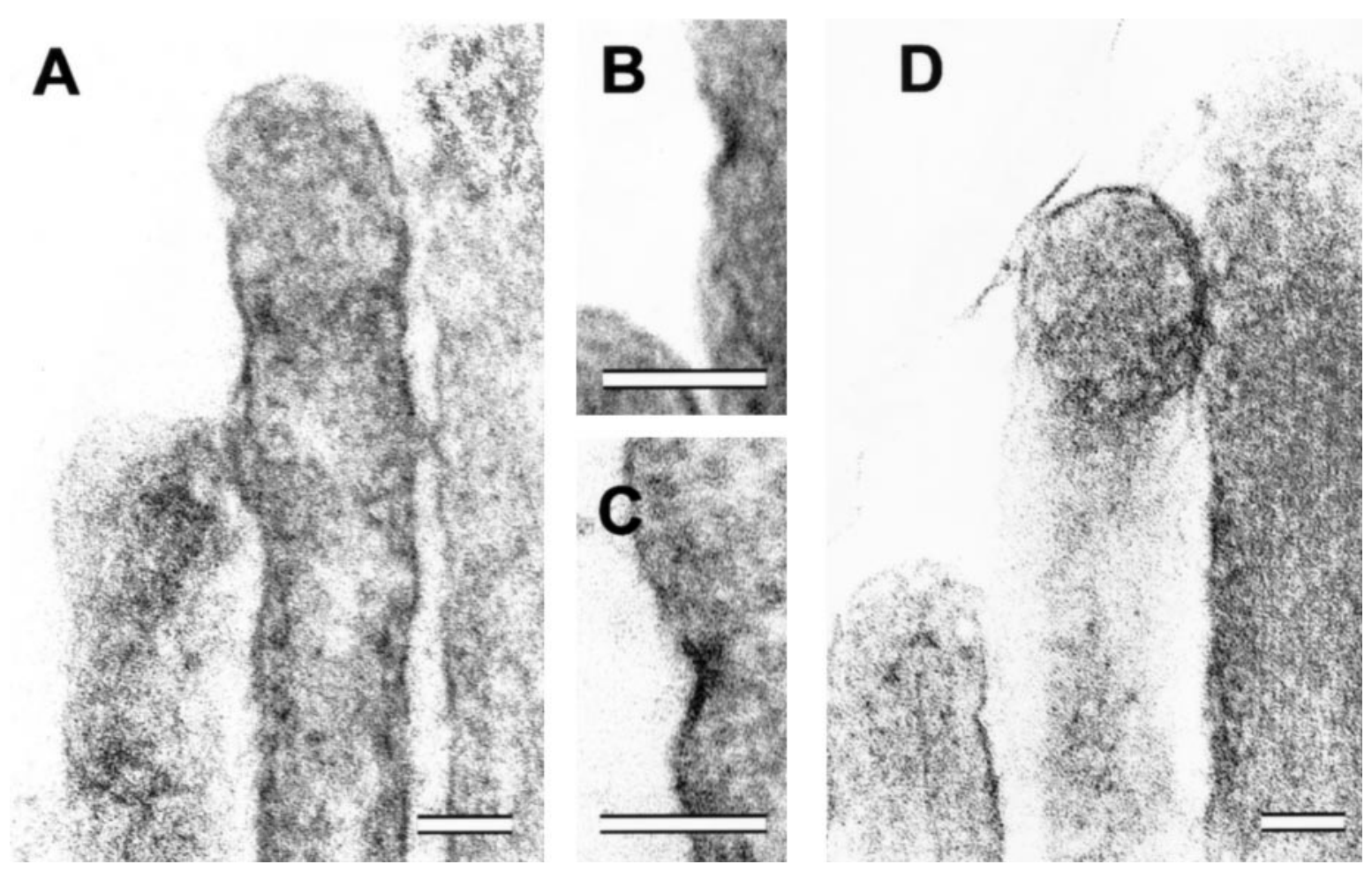

Figure 4. Immunoelectron microscopy controls. Few gold particles were observed when mT2 was preadsorbed with a synthetic peptide derived from the tail region of bullfrog myosin $\mathrm{I} \beta(A, B)$ or replaced with nonimmune serum $(C)$ or blocking serum $(D)$. Scale bars: $100 \mathrm{~nm}$ in $A-D$.

The number of gold particles located in bins containing either a tip or a side plaque, regardless of hair bundle location or morphology, was significantly higher than in bins not containing a plaque $(p<0.0001)$ (Table 1). With the exception of inner striolar hair bundles $(p>0.10)$, this observation was true for hair bundles in different macular regions and for different hair bundle types $(p<0.001)$. There were no significant differences in the number of gold particles between membrane-only bins at the same level of the stereocilium on kinociliary and nonkinociliary sides $(p>0.40)$.

To test more directly the hypothesis that gold immunoreactivity was associated with the side insertional plaque, we examined the distribution of gold particles in and around the plaque, using small square bins (Fig. $8 A$ ). These bins, $75 \times 75 \mathrm{~nm}$, were similar in size to the side plaque, which had a mean diameter of $76 \pm 13$ $\mathrm{nm}[n=64$ bins $]$. As a control, similar bins were used to examine gold particles on the kinociliary side; the number of gold particles per bin on the kinociliary side was essentially constant $(p>0.10$ for all pairwise combinations; Table 2). There was also no significant difference between the number of gold particles in kinociliary bins and the outermost basal $(p>0.10)$ or apical $(p>0.05)$ nonkinociliary bin. Regardless of hair bundle location or morphology, the number of gold particles on the nonkinociliary side was greatest in the bin containing the side plaque and systematically decreased in bins located basally or apically to the density (Fig. $8 C$ ). The number of gold particles in the bin containing the side plaque was significantly greater than in the outermost basal $(p<0.05)$ and apical $(p<0.002)$ bins. This significance was increased greatly when the centralmost bin was pooled with the bins located above and below it and the pooled bins were compared with the apical or basal outermost three bins $(p<0.0001)$, confirming our initial observation that gold immunoreactivity was located immediately adjacent to as well as within the side osmiophilic density.
To compare the overall gold immunoreactivity in the immediate vicinity of the tip and side insertional plaques, we determined the density of gold particles located within arcs of $100 \mathrm{~nm}$ diameter, centered on the tip and side plaques. In the 64 stereocilia that were examined in this study, the gold particle density within $100 \mathrm{~nm}$ of the center of the side plaque $(1.7 \pm 0.5$ gold particles per 1000 square nanometers) was significantly greater than the density within $100 \mathrm{~nm}$ of the center of the tip plaque $(0.9 \pm 0.4$ particles per 1000 square nanometers $)(p<0.05)$ and greater than the control value density $(0.7 \pm 0.4$ per 1000 square nanometers) $(p<0.01)$. The gold particle density of the tip plaque was not significantly different from the control arc.

\section{DISCUSSION}

Morphologically distinct hair cells in the bullfrog utricle differ in their rates and extent of adaptation (Baird, 1994a,b). Recent biochemical, pharmacological, and immunocytochemical studies suggest that myosin $\mathrm{I} \beta$ is responsible for the adaptation of mechanoelectrical transduction current in vestibular otolith hair cells (Gillespie et al., 1993; Walker and Hudspeth, 1996; Yamoah and Gillespie, 1996; Burlacu et al., 1997; Garcia et al., 1997; Hasson et al., 1997). Here, we demonstrate that utricular hair cells of widely varying adaptation kinetics contain myosin $\mathrm{I} \beta$ throughout their hair bundles. In addition, we demonstrate significant concentrations of myosin $\mathrm{I} \beta$ within the insertional plaques that anchor the tip links, providing more compelling evidence that myosin $\mathrm{I} \beta$ is the adaptation motor. Although the the rate of adaptation in utricular hair cells ranges from milliseconds to more than several seconds, all utricular hair cells nevertheless contain myosin I $\beta$ molecules properly placed to perform adaptation.

\section{Myosin $\mathrm{I} \beta$ in utricular stereocilia}

To determine the specificity of $\mathrm{mT} 2$ for myosin $\mathrm{I} \beta$ in utricular hair bundles, we adapted previously published methods for bun- 

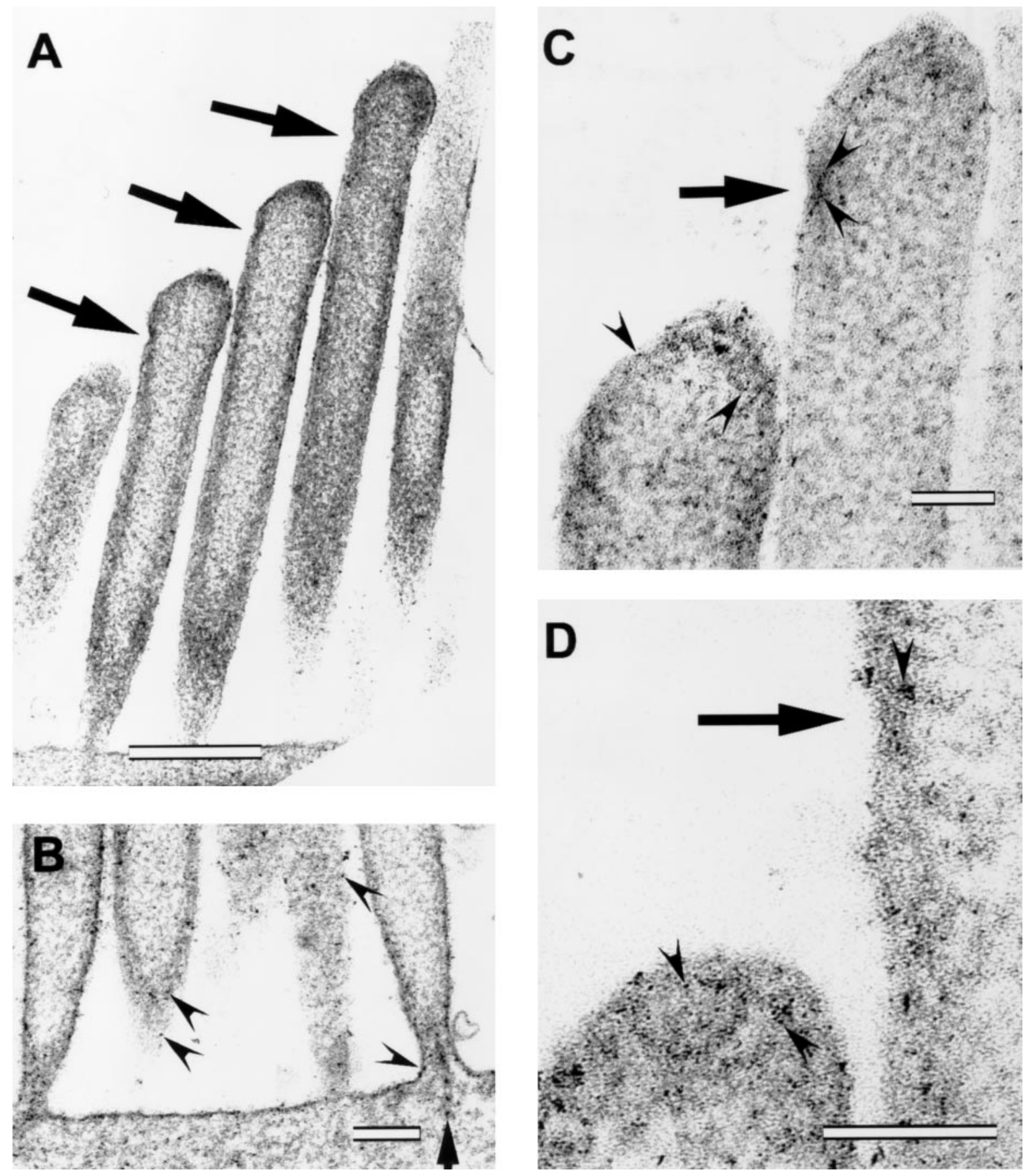

Figure 5. Immunoelectron microscopic localization of myosin $\mathrm{I} \beta$ in extrastriolar hair cells. Shown are the locations of side insertional plaques $(A, C$, $D$, arrows) and gold immunoreactivity $(B-D)$ in medial extrastriolar Type B hair bundles. Note the presence of gold particles in the stereociliary rootlet $(B$, small arrow $)$, ankle region $(B$, arrowheads $)$, side plaques $(C, D$, arrowheads $)$, and stereociliary tips $(C, D$, arrowheads). In $D$, there are 40 counted gold particles, but only three are indicated at the tips of the arrowheads. As an example, the arrowhead on the top right of the panel is pointing to a single gold particle; in addition, there are two clearly identifiable particles immediately below this one. To the right of those two particles is a cluster that would not be included in the particle count because of the difficulty in discerning the number of particles present. Images were obtained at accelerating voltages of $60 \mathrm{kV}(A-C)$ or $80 \mathrm{kV}(D)$. Scale bars: $500 \mathrm{~nm}$ in $A ; 200 \mathrm{~nm}$ in $B ; 100 \mathrm{~nm}$ in $C, D$.

dle isolation (Gillespie and Hudspeth, 1991). By adding sulfoSHPP, a water-soluble primary amine-reactive labeling reagent, we improved substantially the recovery of utricular hair bundles. Protein immunoblotting of purified hair bundles with mT2 demonstrated that the antigen recognized by this antibody is similar in mass to myosin $\mathrm{I} \beta$ in other frog tissues or expressed in insect cells.
These results show that the antibody labels myosin I $\beta$ selectively, justifying its use in immunolabeling experiments.

\section{Myosin I $\beta$ in the side insertional plaque}

In the distal region of each stereocilium, regardless of hair bundle morphology and, hence, adaptation kinetics, myosin I $\beta$ immuno- 

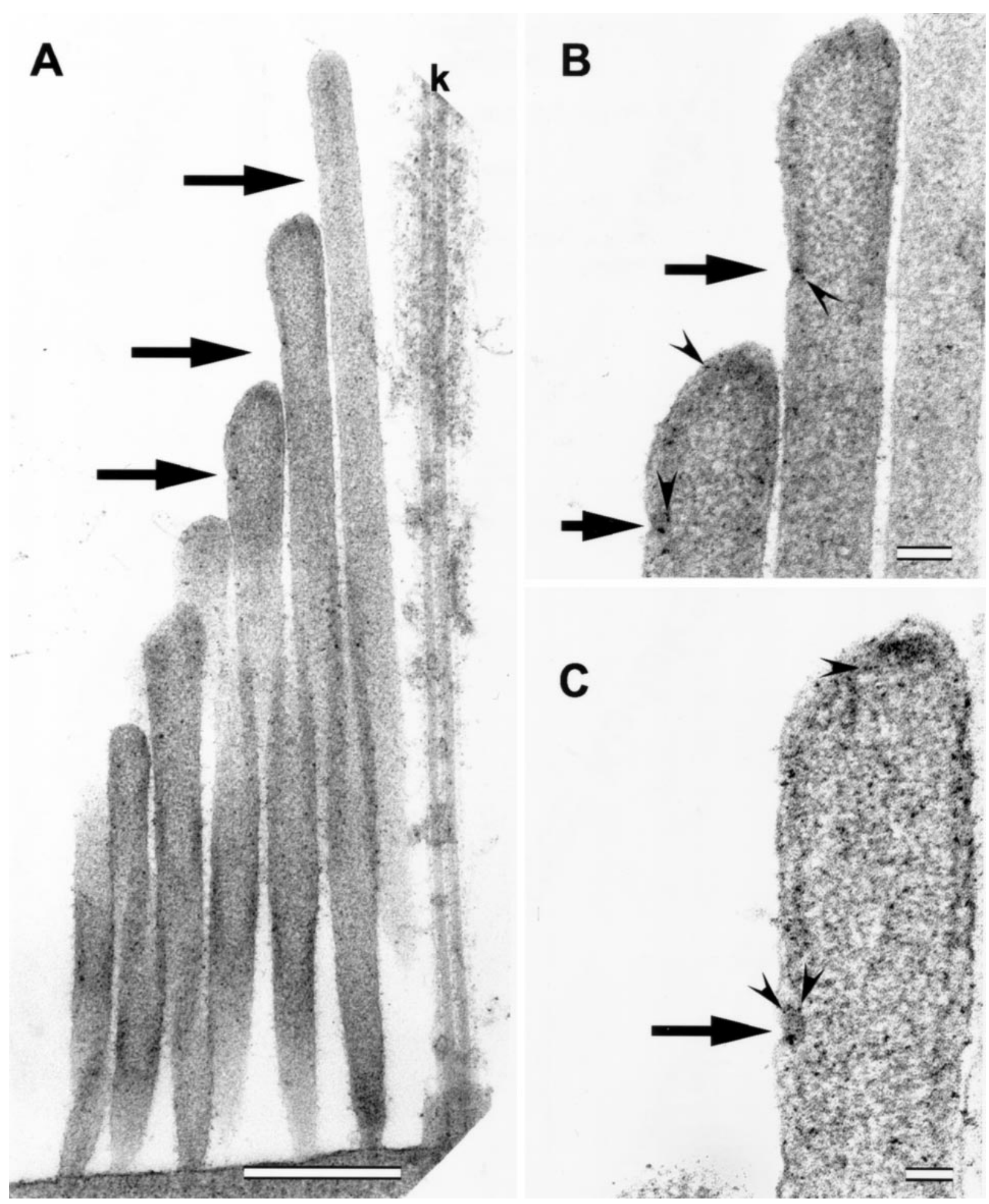

Figure 6. Immunoelectron microscopic localization of myosin I $\beta$ in striolar hair cells. Shown are the locations of side insertional plaques (large arrows, $A-C)$ and gold immunoreactivity $(B, C)$ in stereocilia from an outer striolar Type $\mathrm{C}$ hair bundle. Note the presence of gold particles at the tip and side plaques (arrowheads, $B, C$ ). All images were obtained at an accelerating voltage of $60 \mathrm{kV}$. Scale bars: $500 \mathrm{~nm}$ in $A ; 100 \mathrm{~nm}$ in $B, C$.

reactivity was found within and adjacent to the insertional plaques at the stereociliary tip and on the side of the stereocilium near the tip of the adjacent, shorter stereocilium (see Figs. 5-8). These structures correspond with the insertion points of the tip links (Furness and Hackney, 1985). Gold particles were found at higher density within $200 \mathrm{~nm}$ of each tip insertional plaque and within $75 \mathrm{~nm}$ of each side insertional plaque, as compared with adjacent membrane areas.

Localization at the side insertional plaque lends further support to the hypothesis that myosin $\mathrm{I} \beta$ is the myosin isozyme responsible for adaptation. Myosin molecules are likely to constitute the adaptation motor of the hair cell, which is thought to 

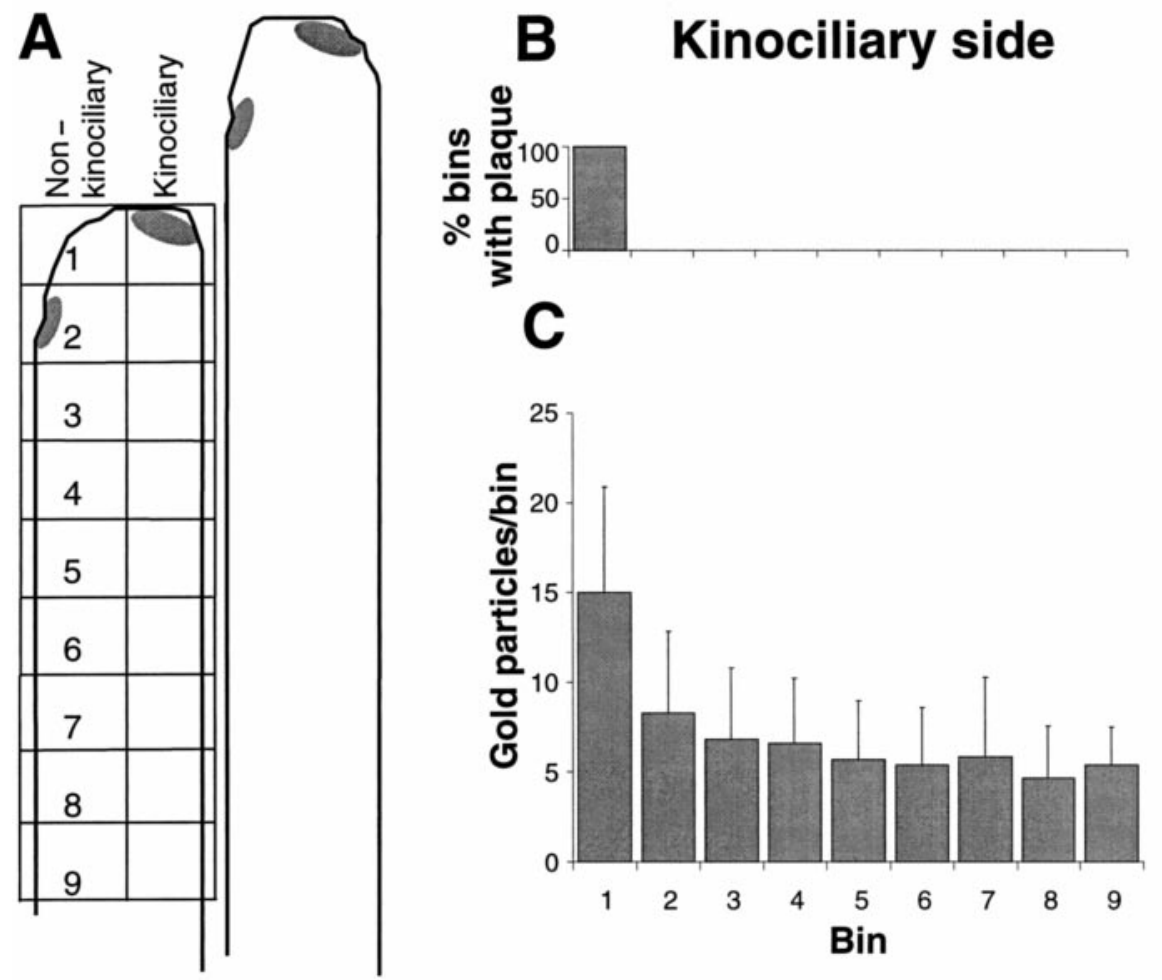

\section{Nonkinociliary side}
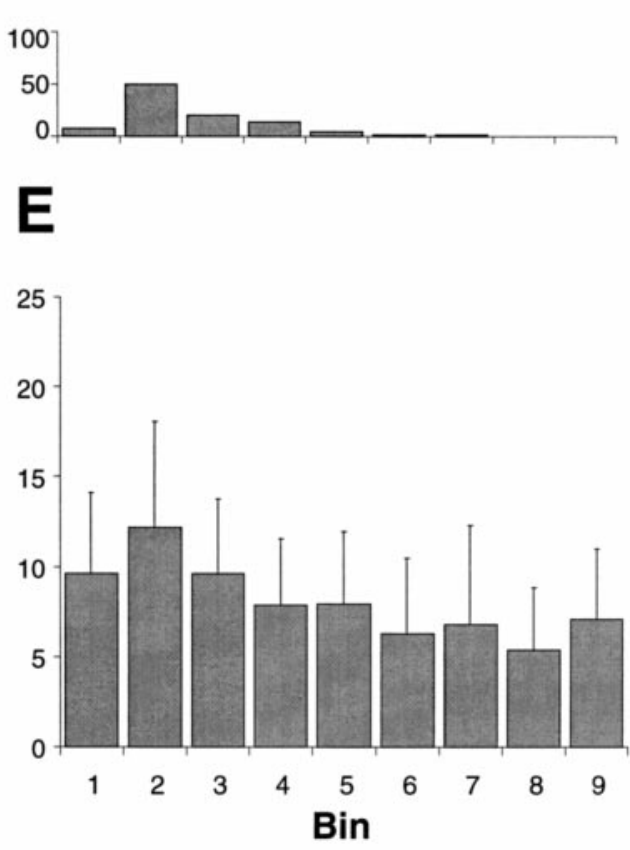

Figure 7. Morphometric analysis of myosin $\mathrm{I} \beta$ localization, using coarse spatial bins. $A$, Schematic diagram of rectangular sampling grid with typical location of tip and side insertional plaques. $B$, Percentage of stereocilia with tip plaques located in the indicated bins. The tip plaque was always located in the apical-most kinociliary bin. $C$, Mean number and SD of gold particles found in each $200 \mathrm{~nm}$ kinociliary bin. $D$, Percentage of stereocilia with side plaques located in the indicated bins. The location of the side plaque on the nonkinociliary side was variable. $E$, Mean number and SD of gold particles found in each $200 \mathrm{~nm}$ nonkinociliary bin.

Table 1. Number of gold particles in $200 \mathrm{~nm}$ rectangular bins

\begin{tabular}{|c|c|c|c|c|}
\hline \multirow{2}{*}{$\begin{array}{l}\text { Hair bundle } \\
\text { types }\end{array}$} & \multirow[b]{2}{*}{$n$} & \multicolumn{3}{|c|}{ BINS } \\
\hline & & Tip insertional plaque & Side insertional plaque & Membrane only \\
\hline All HBs & $64(19)$ & $14.8 \pm 5.8[64]$ & $13.6 \pm 5.7[64]$ & $7.1 \pm 4.1[730]$ \\
\hline All OS & $16(6)$ & $16.0 \pm 7.6[16]$ & $15.1 \pm 7.7[16]$ & $8.0 \pm 4.6[190]$ \\
\hline All IS & $21(6)$ & $12.6 \pm 4.6[21]$ & $12.1 \pm 3.8[21]$ & $6.3 \pm 3.9[64]$ \\
\hline Type B & $27(7)$ & $15.9 \pm 5.2[27]$ & $13.8 \pm 5.4[27]$ & $7.1 \pm 3.8[286]$ \\
\hline Type C & $26(9)$ & $12.4 \pm 5.2[26]$ & $11.1 \pm 4.4[26]$ & $6.0 \pm 3.7[306]$ \\
\hline OS & $8(4)$ & $12.5 \pm 6.0[8]$ & $9.5 \pm 5.3[8]$ & $5.8 \pm 3.5[92]$ \\
\hline IS & $18(5)$ & $12.4 \pm 4.6[18]$ & $11.8 \pm 4.0[18]$ & $6.0 \pm 3.8[214]$ \\
\hline Type F & $8(2)$ & $19.5 \pm 7.7[8]$ & $20.6 \pm 5.5[8]$ & $10.0 \pm 4.6[98]$ \\
\hline Type E & $3(1)$ & $14.0 \pm 2.0[3]$ & $13.7 \pm 2.5[3]$ & $8.0 \pm 4.1[40]$ \\
\hline
\end{tabular}

$n$, Number of individual stereocilia with both tip and side insertional plaques (number of hair bundles in parentheses). Values, means \pm SD of gold particles in $200 \mathrm{~nm}$ bins containing the tip insertional plaque, the side insertional plaque, or membrane only (number of bins in brackets). Gold immunoreactivity in bins containing either the tip or side insertional plaques was significantly greater than in bins containing membrane only for all bundles $(p<0.0001)$, extrastriolar bundles (Type B) $(p<0.001)$, and outer striolar bundles $(p<0.001)$. HBs, Hair bundles; OS, outer striolar (i.e., outer striolar Type $\mathrm{C}$ and Type F) hair bundles; IS, inner striolar (i.e., inner striolar Type $\mathrm{C}$ and Type $\mathrm{E}$ ) hair bundles.

reside in or near the side plaque (Corey and Assad, 1992; Hudspeth and Gillespie, 1994; Gillespie and Corey, 1997). Our results coincide well with localization, using a different antibody against myosin $\mathrm{I} \beta$, both with preliminary results (Hasson et al., 1997) and with a statistical analysis of gold particle location within serial section reconstructions of several hair bundles (Garcia et al., 1997; D. Corey, personal communication). Although another immunoelectron microscopic investigation failed to find a corre- lation between myosin $\mathrm{I} \beta$ location and the side plaque (Metcalf, 1998), the labeling density encountered in that study appeared too low to draw meaningful statistical conclusions. The immunoelectron microscopy data obtained so far, therefore, show that myosin $\mathrm{I} \beta$ is concentrated where the adaptation motor is thought to be located and, hence, support its proposed role as the active component of the adaptation motor.

Gold immunoreactivity corresponding to myosin I $\beta$ near the 


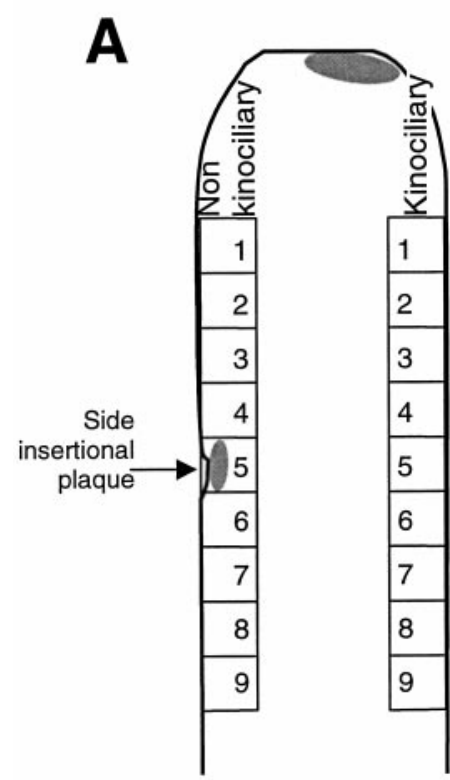

\section{B Kinociliary side C Nonkinociliary side}
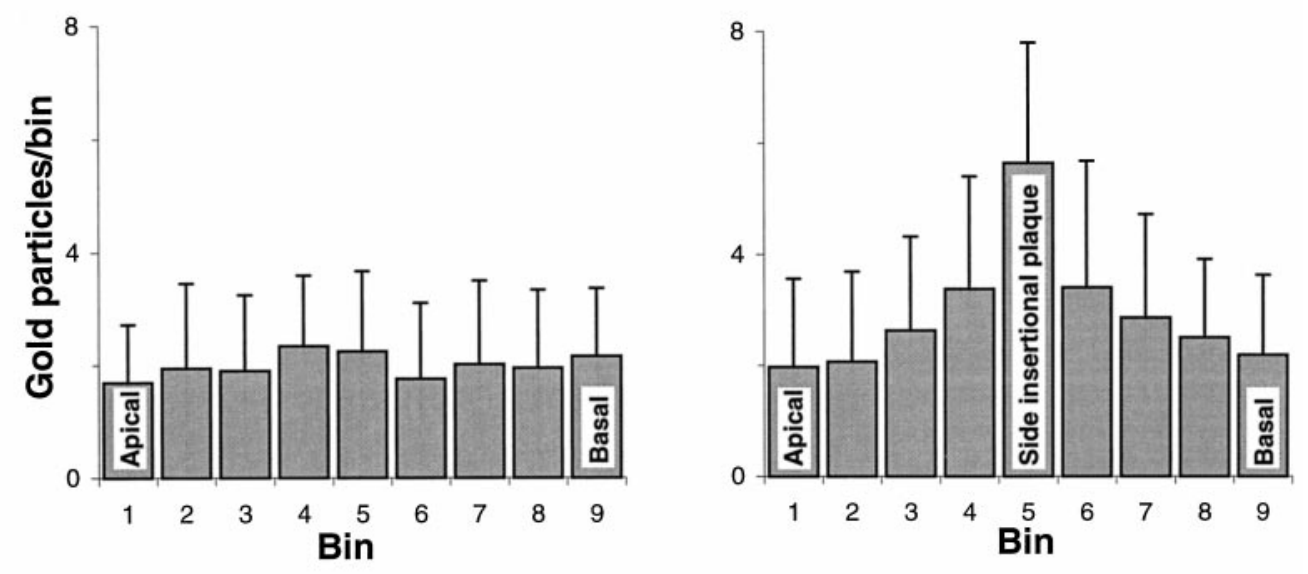

Figure 8. Morphometric analysis of myosin $\mathrm{I} \beta$ localization, using fine spatial bins. $A$, Schematic diagram of $75 \mathrm{~nm}$ square sampling grid with typical location of tip and side insertional plaques. $B$, Mean number and SD of gold particles located in each bin on the kinociliary side. There was no significant difference in the number of gold particles between any two pairs of bins on the kinociliary side of the stereocilium $(p>0.10)$. $C$, Mean number and SD of gold particles located in each bin on the nonkinociliary side. On this side the number of gold particles in the bin containing the side plaque was significantly greater than that in basal or apical bins located $>200 \mathrm{~nm}$ from the side plaque $(p<0.05)$.

Table 2. Number of gold particles in $75 \mathrm{~nm}$ square bins

Kinociliary side

\begin{tabular}{|c|c|c|c|c|c|c|c|c|c|c|}
\hline \multirow{2}{*}{$\begin{array}{l}\text { Hair } \\
\text { bundle } \\
\text { types }\end{array}$} & \multirow[b]{2}{*}{$n$} & \multicolumn{2}{|l|}{ apical } & & & \multicolumn{4}{|l|}{ BINS } & \multirow{2}{*}{$\begin{array}{l}\text { basal } \\
9\end{array}$} \\
\hline & & 1 & 2 & 3 & 4 & 5 & 6 & 7 & 8 & \\
\hline
\end{tabular}

All HBs 63 (19) $1.7 \pm 1.0[13] 2.0 \pm 1.5[19] \quad 1.9 \pm 1.4[31] 2.3 \pm 1.3[44] 2.2 \pm 1.4[52] 1.8 \pm 1.4[62] 2.0 \pm 1.5$ [63] $2.0 \pm 1.4$ [63] $2.2 \pm 1.2$ [62]

\begin{tabular}{|c|c|c|c|c|c|c|c|c|c|}
\hline & \multicolumn{9}{|c|}{ Nonkinociliary side } \\
\hline & apical & & & & BINS & & & & basal \\
\hline$n$ & 1 & 2 & 3 & 4 & 5 (SIP) & 6 & 7 & 8 & 9 \\
\hline
\end{tabular}

All HBs 64 (19) $2.0 \pm 1.6[36] 2.1 \pm 1.6[46] 2.6 \pm 1.7[60] 3.4 \pm 2.0[64] \quad 5.6 \pm 2.2[64] 3.4 \pm 2.3[64] 2.9 \pm 1.9$ [64] $2.5 \pm 1.4$ [64] $2.2 \pm 1.4$ [62]

$\begin{array}{lllllllllll}\text { OS } & 16(6) & 1.5 \pm 2.3[6] & 2.3 \pm 1.9[10] & 2.8 \pm 2.4[13] & 3.5 \pm 2.5[16] & 5.8 \pm 1.8[16] & 5.0 \pm 3.0[16] & 3.7 \pm 2.2[16] & 2.8 \pm 2.0[16] & 2.6 \pm 1.8[16]\end{array}$

IS $\quad 21(6) \quad 2.2 \pm 1.3[19] 1.9 \pm 1.5[20] 2.6 \pm 1.5[21] \quad 3.0 \pm 1.9[21] 5.2 \pm 1.7[21] 2.8 \pm 1.8[21] 2.3 \pm 1.9[21] 2.1 \pm 1.3[21] \quad 1.8 \pm 1.0[20]$

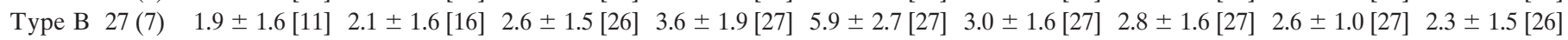

Type C $26(9) \quad 1.8 \pm 1.5[21] \quad 1.9 \pm 1.5[23] 2.4 \pm 1.6[26] 2.7 \pm 1.9[26] 4.9 \pm 1.5[26] 2.7 \pm 1.7[26] 2.4 \pm 1.9$ [26] $1.9 \pm 1.3$ [26] $1.4 \pm 0.8$ [25]

OS $8(4) \quad 1.6 \pm 2.6[5] \quad 2.3 \pm 1.6[6] \quad 2.0 \pm 1.9[8] \quad 2.0 \pm 1.9[8] \quad 4.8 \pm 1.2[8] \quad 2.9 \pm 1.7[8] \quad 2.8 \pm 1.9[8] \quad 1.3 \pm 0.9[8] \quad 1.3 \pm 0.7[8]$

IS $18(5) \quad 1.8 \pm 1.1[16] 1.7 \pm 1.4[17] 2.6 \pm 1.6[18] 2.9 \pm 1.9[18] \quad 5.0 \pm 1.7[18] 2.6 \pm 1.8[18] 2.2 \pm 2.0[18] 2.2 \pm 1.4[18] \quad 1.5 \pm 0.8[17]$

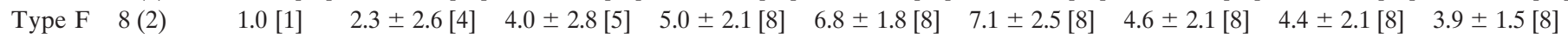

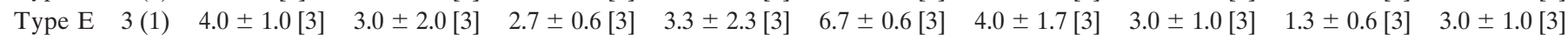

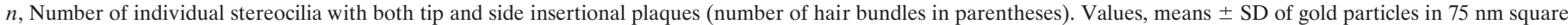

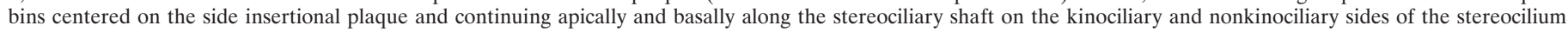

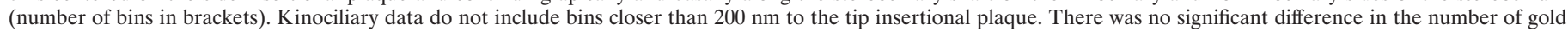

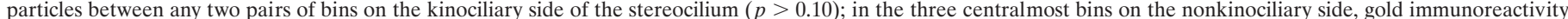

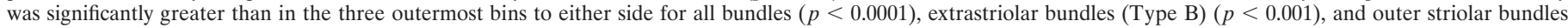

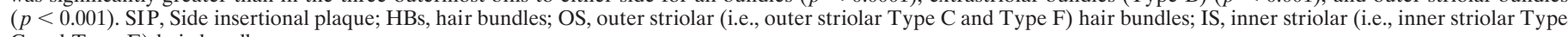
$\mathrm{C}$ and Type E) hair bundles.

side insertional plaque was observed most frequently around the plaque, rather than within it. One view of the side plaque is that it contains 50-100 tightly packed myosin molecules (Hudspeth and Gillespie, 1994; Gillespie and Corey, 1997); with such a structure, antibodies may be excluded sterically from the central regions of aldehyde-fixed plaques. Alternatively, myosin I $\beta$ may not form the side plaque as previously suggested. Instead, the central core of the plaque could be constituted of other, unknown molecules, with myosin $\mathrm{I} \beta$ hovering around the periphery of the plaque. 


\section{Myosin I $\beta$ within the stereocilia}

In addition to its concentration in insertional plaques, we also found myosin $\mathrm{I} \beta$ at the membrane along the stereociliary shaft and adjacent to the apical membrane over the cuticular plate. Myosin I $\beta$ also was observed in the ankle region, where each stereocilium tapers as its rootlet enters the cuticular plate. Occasional myosin I $\beta$ immunoreactivity was associated with the rootlet within the cuticular plate. The rootlets might serve as a track for initiating myosin I $\beta$ movement into stereocilia; alternatively, myosin I $\beta$ might participate in cross-linking rootlet actin filaments to the cuticular plate, as hypothesized for myosin VI (Hasson et al., 1997).

The majority of myosin $\mathrm{I} \beta$ molecules at stereociliary tips was associated with the tip insertional plaque, at the lower end of the tip link. If the transduction apparatus is symmetric, with channels and motors at either end of a tip link (Denk et al., 1995), myosin $\mathrm{I} \beta$ would be expected at this position, although it should not play an active role in adaptation. Other myosin $\mathrm{I} \beta$ molecules may be found at stereociliary tips because of the dynamic nature of the transduction apparatus (Zhao et al., 1996); recycled or unused adaptation motor myosin molecules may accumulate at the ends of their actin tracks. Not all myosin $\mathrm{I} \beta$ is at distal regions of the stereocilia, however; some mechanism must exist to shuttle motor molecules back to the soma or to degrade them at stereociliary tips.

\section{Modification of adaptation rate in utricular hair cells}

Our experiments indicate that gross inequities in myosin $\mathrm{I} \beta$ distribution cannot account for the range of adaptation kinetics seen in utricular hair cells. If hair cells have similar amounts of myosin I $\beta$ within their adaptation motors, despite differing adaptation kinetics, how do these different cell types regulate their adaptation rates? Several explanations can account for these differences.

The rate of adaptation depends on both the force applied to the adaptation motor and on the concentration of $\mathrm{Ca}^{2+}$ felt by the motor (Assad and Corey, 1992), as well as on the number of myosin molecules in an adaptation motor and on their kinetic and mechanical properties (Gillespie and Corey, 1997). Although increasing the number of myosin molecules per adaptation motor could reduce the rate of slipping adaptation, we saw no correlation between myosin $\mathrm{I} \beta$ immunoreactivity in side insertional plaques and the adaptation rate of the utricular hair cell types.

Differences in adaptation rate also could arise from variations in the concentration or association kinetics of mobile $\mathrm{Ca}^{2+}$ buffers (Ricci and Fettiplace, 1997). Utricular hair cells contain the mobile $\mathrm{Ca}^{2+}$ buffers calbindin, calretinin, calmodulin, parvalbumin, and S-100 (Baird et al., 1997). Cells with high levels of $\mathrm{Ca}^{2+}$ buffers should adapt more slowly than those with lower amounts. Although variations in $\mathrm{Ca}^{2+}$ buffer distribution are seen within the bullfrog utricle (Baird et al., 1997), it seems unlikely that these variations could account for the differences seen in the adaptation rate.

Adaptation kinetics also might be affected by the concentration of calmodulin, a critical regulator of myosin I $\beta$ (Barylko et al., 1992; Zhu et al., 1996), including myosin I $\beta$ of the hair bundle (Walker and Hudspeth, 1996). Detectable calmodulin immunoreactivity is absent from nonadapting extrastriolar hair cells within the utricle (Baird et al., 1997). Although myosin $\mathrm{I} \beta$ is present in these hair cells, the diminished calmodulin concentration in these cells may limit the myosin activity. Different permutations of myosin $\mathrm{I} \beta$ and $\mathrm{Ca}^{2+}$ binding proteins could be responsible for the range of adaptation kinetics seen in different utricular hair cell types. Because additional mechanisms may account for the variability of adaptation, however, further investigation certainly will be required to establish definitively why adaptation rates vary in these cell types.

\section{Universality of the adaptation motor}

Our results confirm that myosin $\mathrm{I} \beta$ is present in all utricular hair cells, even those that do not adapt appreciably to sustained displacements. This apparent discrepancy may reflect different time scales of adaptation in different hair cell types. The central role of adaptation is to ensure that the tension applied to gating springs is optimal so that transduction channels can respond sensitively to displacements (Howard and Hudspeth, 1987b; Howard et al., 1988). For example, although type B hair cells do not adapt to stimuli as long as $2 \sec$ (Baird, 1994b), myosin I $\beta$ is present at the side insertional plaque of type B hair cells in amounts comparable to amounts in other hair cell types. Instead, the presence of an active motor molecule may account for type B cells being on their displacement-response relation at rest near the steepest and, hence, most sensitive point (Baird, 1994b), a position that should require the substantial application of force to gating springs (Hudspeth, 1992). Rather than being used to reset the transduction apparatus on a time scale of tens of milliseconds, myosin $\mathrm{I} \beta$ (and the adaptation motor) may operate on a much slower time scale in type B cells, presumably with similar $\mathrm{Ca}^{2+}$ feedback. Although precluding rapid adaptation, a slow time scale for the adaptation motor would ensure that these cells nevertheless could detect small stimuli.

Nonadapting hair cells of the bullfrog utriculus are unlikely to be exceptional in possessing the motor molecule responsible for adaptation without also exhibiting rapid adaptation. Setting resting gating spring tension should be a universal requirement for hair cells, and the adaptation motor is well suited to perform this role. We suspect that even hair cells of the mammalian cochlea, which exhibit little or no adaptation (Géléoc et al., 1997) (but see also Kros et al., 1992), also will use such a motor and will be found to have myosin $\mathrm{I} \beta$ located near their tip link anchors.

\section{REFERENCES}

Assad JA, Corey DP (1992) An active motor model for adaptation by vertebrate hair cells. J Neurosci 12:3291-3309.

Assad JA, Shepherd GMG, Corey DP (1991) Tip-link integrity and mechanical transduction in vertebrate hair cells. Neuron 7:985-994.

Baird RA (1992) Morphological and electrophysiological properties of hair cells in the bullfrog utriculus. Ann NY Acad Sci 656:12-26.

Baird RA (1994a) Comparative transduction mechanisms of hair cells in the bullfrog utriculus. I. Responses to intracellular current. J Neurophysiol 71:666-684.

Baird RA (1994b) Comparative transduction mechanisms of hair cells in the bullfrog utriculus. II. Sensitivity and response dynamics to hair bundle displacement. J Neurophysiol 71:685-705.

Baird RA, Schuff NR (1994) Peripheral innervation patterns of vestibular nerve afferents in the bullfrog utriculus. J Comp Neurol 342:279-298.

Baird RA, Steyger PS, Schuff NR (1997) Intracellular distributions and putative functions of calcium-binding proteins in the bullfrog vestibular otolith organs. Hear Res 103:85-100.

Barylko B, Wagner MC, Reizes O, Albanesi JP (1992) Purification and characterization of a mammalian myosin I. Proc Natl Acad Sci USA 89:490-494.

Burlacu S, Tap WD, Lumpkin EA, Hudspeth AJ (1997) ATPase activity of myosin in hair bundles of the bullfrog's sacculus. Biophys $\mathrm{J}$ $72: 263-271$

Corey DP, Assad JA (1992) Transduction and adaptation in vertebrate hair cells: correlating structure with function. In: Sensory transduction (Corey DP, Roper SD, eds), pp 326-342. New York: Rockefeller UP. 
Corey DP, Hudspeth AJ (1983) Kinetics of the receptor current in bullfrog saccular hair cells. J Neurosci 3:962-976.

Denk W, Holt JR, Shepherd GM, Corey DP (1995) Calcium imaging of single stereocilia in hair cells: localization of transduction channels at both ends of tip links. Neuron 15:1311-1321.

Eatock RA, Corey DP, Hudspeth AJ (1987) Adaptation of mechanoelectric transduction in hair cells of the bullfrog's sacculus. J Neurosci 7:2821-2836.

Furness DN, Hackney CM (1985) Cross-links between the stereocilia in the guinea pig cochlea. Hear Res 18:177-188.

Garcia JA, Yee AG, Hasson T, Gillespie PG, Corey DP (1997) Localization of myosin $\mathrm{I} \beta$ in frog saccular hair cells using confocal and immunoelectron microscopy. ARO Midwinter Meeting Abstr 20:233.

Géléloc GSG, Lennan GWT, Richardson GP, Kros CJ (1997) A quantitative comparison of mechanoelectrical transduction in vestibular and auditory hair cells of neonatal mice. Proc R Soc Lond [Biol] 264:611-621.

Gillespie PG, Corey DP (1997) Myosin and adaptation by hair cells. Neuron 19:955-958.

Gillespie PG, Gillespie SKH (1997) Improved electrophoresis and transfer of picogram amounts of protein with hemoglobin. Anal Biochem 246:239-245.

Gillespie PG, Hudspeth AJ (1991) High-purity isolation of bullfrog hair bundles and subcellular and topological localization of constituent proteins. J Cell Biol 112:625-640.

Gillespie PG, Wagner MC, Hudspeth AJ (1993) Identification of a 120 kd hair-bundle myosin located near stereociliary tips. Neuron 11:581-594.

Hasson T, Gillespie PG, MacDonald RB, Garcia J, Zhao Y-D, Yee AG, Mooseker MS, Corey DP (1997) Unconventional myosins in inner-ear sensory epithelia. J Cell Biol 137:1287-1307.

Howard J, Hudspeth AJ (1987a) Mechanical relaxation of the hair bundle mediates adaptation in mechanoelectrical transduction by the bullfrog's saccular hair cell. Proc Natl Acad Sci USA 84:3064-3068.

Howard J, Hudspeth AJ (1987b) Adaptation of mechanoelectrical transduction in hair cells. In: Sensory transduction (Hudspeth AJ, MacLeish PR, Margolis FL, Wiesel TN, eds), pp 138-145. Geneva: Fondation pour l'Etude du Système Nerveux Central et Périphérique.

Howard J, Roberts WM, Hudspeth AJ (1988) Mechanoelectrical transduction by hair cells. Annu Rev Biophys Chem 17:99-124.

Hudspeth AJ (1983) Transduction and tuning by vertebrate hair cells. Trends Neurosci 6:366-369.

Hudspeth AJ (1992) Hair-bundle mechanics and a model for mechano- electrical transduction by hair cells. In: Sensory transduction (Corey DP, Roper SD, eds), pp 357-370. New York: Rockefeller UP.

Hudspeth AJ, Gillespie PG (1994) Pulling strings to tune transduction: adaptation by hair cells. Neuron 12:1-9.

Jaramillo F, Hudspeth AJ (1993) Displacement-clamp measurement of the forces exerted by gating springs in the hair bundle. Proc Natl Acad Sci USA 90:1330-1334.

Kros CJ, Rüsch A, Richardson GP (1992) Mechanoelectrical transducer currents in hair cells of the cultured neonatal mouse cochlea. Proc R Soc Lond [Biol] 249:185-193.

Lewis ER, Li CW (1975) Hair cell types and distributions in the otolithic and auditory organs of the bullfrog. Brain Res 83:35-50.

Lewis ER, Baird RA, Leverenz EL, Koyama H (1982) Inner ear: dye injection reveals peripheral origins of specific sensitivities. Science 215:1641-1643.

Metcalf AB (1996) Molecular characterization of amphibian myosin I, a candidate for the hair bundle's adaptation motor. PhD thesis, University of Texas Southwestern Medical Center, Dallas, TX.

Metcalf AB (1998) Immunolocalization of myosin I $\beta$ in the hair cell's hair bundle. Cell Motil Cytoskeleton 39:159-165.

Pickles JO, Comis SD, Osborne MP (1984) Cross-links between stereocilia in the guinea pig organ of Corti, and their possible relation to sensory transduction. Hear Res 15:103-112.

Ricci A, Fettiplace R (1997) The effects of calcium buffering and cyclic AMP on mechanoelectrical transduction in turtle auditory hair cells. J Physiol (Lond) 501:111-124.

Solc CK, Derfler BH, Duyk GM, Corey DP (1994) Molecular cloning of myosins from the bullfrog saccular macula: a candidate for the adaptation motor. Aud Neurosci 1:63-75.

Wagner MC, Barylko B, Albanesi JP (1992) Tissue distribution and subcellular localization of mammalian myosin I. J Cell Biol 119:163-170.

Walker RG, Hudspeth AJ (1996) Calmodulin controls adaptation of mechanoelectrical transduction by hair cells of the bullfrog's sacculus. Proc Natl Acad Sci USA 93:2203-2207.

Yamoah EN, Gillespie PG (1996) Phosphate analogs block adaptation in hair cells by inhibiting adaptation-motor force production. Neuron 17:523-533.

Zhao YD, Yamoah EN, Gillespie PG (1996) Regeneration of broken tip links and restoration of mechanical transduction in hair cells. Proc Natl Acad Sci USA 93:15469-15474.

Zhu T, Sata M, Ikebe M (1996) Functional expression of mammalian myosin I $\beta$ : analysis of its motor activity. Biochemistry 35:513-522. 